\title{
LATINOAMÉRICA Y LA CULTURA EN EL SIGLO XXI*
}

\author{
Margarita Giesecke Sara Lafosse \\ HISTORIADORA Y \\ PROFESORA AFILIADA DE ESAN
}

\section{Resumen}

Aborda la cultura latinoamericana desde la perspectiva de la historia y como tema esencial para comprender la complejidad del problema del subdesarrollo. Examina qué se entiende por cultura, traza la historia de la formación de la cultura latinoamericana y señala el papel que a ésta le debería corresponder para superar el subdesarrollo en el contexto de un mundo globalizado. Sostiene que la democracia comunicacional y la educación son las alternativas para la forja de identidades culturales en capacidad de negociar con la globalización.

$E_{1}$ tema que hoy nos convoca es el de a cultura latinoamericana en el siglo XXI. A pesar de que al parecer de una mayoría, y en especial de los economistas y hacedores de políticas, la cultura es una cuestión secundaria, en realidad es un tema crucial para comprender la complejidad del problema del subdesarrollo.

Enfocamos la cultura desde la historia y ésta, a diferencia de otras ciencias, nos facilita una visión comprehensiva y de largo aliento. El conocimiento del pro-

* Conferencia dictada durante la sesión inaugural del sétimo congreso internacional de la Western Academy of Management. Lima, 6 de julio de 2002. ceso y de las tendencias del acontecer histórico nos ofrece la ventaja de permitirnos acortar la brecha que separa el presente del futuro, aun cuando quienes nos dedicamos a la historia no somos ni presumimos de gurús ni de pitonisas.

En primer lugar, es importante explicar lo que entendemos por cultura. Enseguida es preciso trazar, a grandes rasgos, la historia de la formación de la cultura latinoamericana y el papel que a ésta le ha correspondido en el subdesarrollo. Finalmente, señalaremos la complejidad de la cultura y las múltiples entradas al tema, así como el papel que a la cultura le debería corresponder para superar el subdesa- 
rrollo hoy día, en el contexto de un mundo que se globaliza.

\section{1. ¿Qué entendemos por cultura?}

Por cultura entendemos la capacidad que tienen los pueblos de crear respuestas satisfactorias de tipo material, mental y espiritual a sus necesidades vitales. Es la capacidad de satisfacer armoniosa y coherentemente la necesidad de alimentarse, vestirse, cobijarse, trabajar y producir todo tipo de arte, ciencia, tecnología y religión o cosmovisión. La cultura, entonces, se refiere a una particular manera de ver el mundo y de relacionarse con él. Históricamente, las culturas de las naciones coherentes con su entorno, su gente y su historia han logrado dar identidad a las distintas colectividades humanas que en la historia universal han existido, incluso con anterioridad a las antiguas civilizaciones, y que hoy sobreviven al nuevo orden global que parece orientado a prescindir de las naciones.

Es preciso recordar que la cultura es algo vivo, tan vivo como los seres humanos que la producen y, por ende, cambiante en el tiempo. La cultura y las culturas de los pueblos son, entonces, el resultado de largos procesos de acumulación del conocimiento y la matriz inconfundible de su identidad.

En este sentido, no existen culturas superiores e inferiores, lo que existen son culturas de mayor o menor complejidad y culturas más o menos exitosas frente a culturas poco exitosas. Un ejemplo por excelencia de lo que queremos decir lo tenemos en el caso de la selva amazónica o 'Rain Forest'. Si ésta existe todavía como uno de los principales pulmones del planeta, a pesar de todas las amenazas que se ciernen sobre ella, es precisamente porque los pueblos que la habitaron durante siglos (15 ó 20 siglos), y aún la habitan, desarrollaron la sabiduría necesaria para servirse de ella sin destruirla. Y fue precisamente la llegada de la demanda extractiva de Occidente (del caucho, en el caso del Perú y Brasil), a fines del siglo XIX e inicios del XX, la que comenzó el inexorable proceso depredatorio y destructivo de los pueblos amazónicos.

La creación de cultura no está necesariamente supeditada al éxito económico de una nación o al lugar 'marginal' que un grupo pueda tener en una nación. Ésta tiene vida propia en cuanto es una respuesta inherente al ser humano inserto en una colectividad. Un ejemplo de esto es la historia del jazz: una forma musical hoy reconocida universalmente y que fue creada por los grupos más desfavorecidos económicamente dentro de la nación que los albergaba.

Esto demuestra que el tema de la cultura y de las culturas amerita varias entradas o perspectivas analíticas.

Si hablamos de la cultura nacional o más aún de la cultura regional, en este caso latinoamericana, y nos ceñimos a nuestra definición primigenia, es decir, la cultura como toda manifestación material (ciencia, tecnología, economía ) y espiritual de un pueblo, encontraremos que nuestras naciones reflejan nítidamente la pérdida gradual de la capacidad de crear esa cultura. La evaluación del bienestar económico, de la calidad de vida y de la producción de conocimiento nos ha merecido el calificativo de 'subdesarrollados'. 
Sin embargo, sí tenemos la capacidad de crear otras dimensiones de cultura, porque podemos plasmar toda nuestra vida cotidiana en nuestra música, literatura, canto, baile, cine, comidas y costumbres, todo lo cual es también manifestación de una gran riqueza espiritual.

En este sentido, su historia aleja a la cultura de América Latina de la definición de cultura como la total capacidad de creación o la plena realización cultural (que incluya la ciencia y la tecnología) y, más bien, la acerca, como acertadamente lo dice Juan Luis Mejía Arango, a la cultura: "como todo aquello que media entre la realidad y los sueños' 1 .

\section{Historia de la cultura en Latinoamérica}

Latinoamérica es el resultado de una particular fusión de culturas preexistentes y de los tiempos o ‘tempo histórico' en que éstas se encontraron con Occidente. Debo anotar que los historiadores no estamos de acuerdo con utilizar la palabra encuentro; para muchos, la frase 'choque de culturas' es más acertada.

Aun cuando aquello ocurrió en el primer tercio del siglo XVI, es decir, hace cerca de quinientos años, la supervivencia de la 'cultura andina', el 'trauma de la conquista' y 'la herencia colonial' todavía parecen explicar, para varios pueblos latinoamericanos y en particular para los peruanos, mucho de lo que hoy acontece.

A nuestro parecer, este fenómeno no se debería principalmente a una fijación atemporal (algo así como a un trágico 'mito de origen'), sino más bien a una suerte de combinación de la memoria co-

1. Ministro de Cultura de Colombia (2001) lectiva de nuestros orígenes como naciones con la recreación permanente de formas, a veces sincréticas y otras híbridas o anacrónicas, de la emergente cultura inicialmente llamada hispanoamericana y luego latinoamericana.

Si tuviéramos que elegir una palabra clave para trabajar el éxito o fracaso de nuestra cultura latinoamericana escogeríamos 'identidad'.

La cultura andina, perfectamente identificable, dejó huellas que los etnohistoriadores han explorado y por las cuales ha sido considerada como una cultura armoniosa y coherente. Esto no quiere decir que se trató del paraíso en la tierra o de la materialización de la Utopía de Tomás Moro. Simplemente quiere decir que se trató de un conjunto de culturas que se relacionaron de múltiples formas para lograr exitosamente una identificación con un mundo perfectamente organizado $y$ proveedor de sentido. La jerarquía social, el dios Sol y demás deidades, la organización laboral, la relación no depredadora con el medio, la producción suficiente y hasta en exceso para sus necesidades, su cosmovisión, astronomía, técnicas hidráulicas y festividades, nos hablan de una cultura más bien exitosa. Lo primordial habría sido la identificación de los unos con los otros y con objetivos comunes. Es decir, el alto desarrollo de una lógica andina para la vida.

Con la conquista, Occidente trajo consigo su propia lógica europea, producto de su propia historia y desarrollos. Los españoles trajeron su visión del mundo, desde el Cristianismo, es decir el monoteísmo; desde la guerra santa y de reconquista de los territorios tomados por los árabes para su rey; desde su particular 
sentido y vivencia de la jerarquía social de corte netamente feudal y sus valores mercantiles inherentes a su gran empresa. No debemos olvidar que la conquista de América fue, antes que nada, una gran empresa comercial.

El 'choque de culturas' acarreó consecuencias inmediatas que configuraron una hecatombe para el mundo andino. Se diezmó la población (por guerras, plagas y sobreexplotación), se desorganizaron los referentes espaciales de los pueblos conquistados, se derrotó a los dioses locales imponiéndose al dios cristiano y se destruyó el orden social, político y económico. La desestructuración del mundo andino sumió a lo que quedó de la población nativa en la desesperanza y el llamado 'desgano vital', fenómeno que, a decir de los demógrafos, provocó inclusive la infertilidad en las mujeres andinas. Pero, esta población debía ser preservada para montar el orden colonial. Sólo ellos podrían producir lo que la Corona española demandaba del nuevo mundo: el oro y la plata. A cuarenta años de la conquista, el mundo hispano peruano fue reorganizado en función de esta demanda. Se creó entonces la República de Españoles y la República de Indios, dos mundos interconectados en los servicios ( o servidumbre) cotidianos, en la producción en las minas, los campos y las ciudades. Sometidos, los andinos aprendieron a sobrevivir con los nuevos códigos de castas, excluyentes y segregacionistas, traídos por los españoles.

Entre los resultados más duraderos y profundos de esta separación de mundos estuvo el olvido de la relación armoniosa con el medio andino y, sobre todo, la desidentificación ex profeso de los unos con los otros y de todos con un único objetivo como nación o, inclusive, como conjunto de naciones.

Fue claro que el mundo colonial no sería una sola nación sino varias naciones en una, sometida a la Corona española. Concomitante a la desidentificación y a la exclusión, se produjo la gradual pérdida del conocimiento acumulado por la cultura andina. Se preservaron algunos usos y costumbres, otros se transformaron por influencia de lo hispano y así se originó el mestizaje que comenzó a definir a la América Latina. Criollos y mestizos pugnaron por desidentificarse con España y por identificarse con el nuevo mundo. Un proceso que en ningún momento incluyó a los indígenas ni a todos aquellos considerados como pertenecientes a las castas inferiores.

Fue en este mundo de vencidos y vencedores que surgió la coyuntura independentista. El imperio inglés deseaba fervientemente 'heredar' las colonias españolas. Las reformas comerciales no pudieron detener la fuerza de la expansión del capital y del comercio de Gran Bretaña, la que financió gran parte de la gesta de la Independencia. Es todavía materia de discusión si la Independencia fue concedida o ganada. Con todo lo importante que resulta este debate, el hecho es que América se liberó de España y pasó a relacionarse comercialmente con el resto de Europa, principalmente con Gran Bretaña.

Los hombres visionarios de América, como Simón Bolívar, fueron muy claros al advertir los peligros de liberalismo o del 'Imperialismo del libre comercio', como nos lo recuerda el historiador Paul Gootemberg. Dos trampas históricas de los nacientes estados latinoamericanos 
fueron: el dogma del libre comercio y la ausencia de nación. En estas tierras, a diferencia de Europa, el Estado nacía antes de la existencia de la nación, entendida ésta como pueblo estructurado. Tan es así que podemos afirmar que la historia republicana de la región está signada, a lo largo de los siglos XIX y XX, por el largo $\mathrm{y}$ doloroso proceso de formación de naciones.

La complejidad de la herencia de la 'cultura colonial' en la creación de las nacientes repúblicas latinoamericanas se reflejó en la autonegación de la capacidad cultural, tanto de los pueblos primigenios u originarios como de los criollos y los mestizos.

Desde su nacimiento como conjunto de repúblicas decimonónicas, América Latina fue objeto de discusión ininterrumpida, por parte de los criollos y mestizos responsables de organizarla, respecto a su escasa potencialidad creadora frente a los logros, conocimiento, bienes manufacturados y de capital que la cultura europea y norteamericana ofrecían y en algunos casos, más bien, imponían. Los tratados comerciales preferenciales y la llamada 'diplomacia de las cañoneras' o 'gunboat diplomacy' así lo confirman.

A partir de allí, América Latina en su conjunto ha vivido tres grandes ciclos de crecimiento económico y de grandes transformaciones sociales y políticas.

El primero es el ciclo marcado por la Era Internacional del Capital, desde la década de 1840 hasta la Gran Depresión de 1873. Este ciclo impuso a América Latina la condición de exportadora de materias primas.
El segundo ciclo, coincidente con la expansión del mercado internacional producida desde fines de 1800 hasta la Crisis de 1929, introdujo a las naciones latinoamericanas de lleno al modelo primario exportador.

Finalmente, el tercer ciclo abarca la Segunda Guerra Mundial, la Guerra de Corea y todo lo bueno que trajo la Edad Dorada de los años cincuenta a los setenta. Este ciclo concluyó con la crisis del petróleo de principios de los años setenta. Podemos identificar este periodo como la Era de Reformas, caracterizado por una permanente alternancia entre las políticas proteccionistas y las liberales.

Las crisis recurrentes de los ochenta desembocaron en un renovado dogma liberal. Es así como en la década de los noventa se nos volvió a presentar la vieja historia del liberalismo bajo el nombre de 'economía de mercado' y proceso de globalización.

Cada ciclo económico ha dejado huella en la evolución de la identidad de estas naciones. Las opciones del siglo XIX fueron brillantemente descritas por Juan Bautista Alberti en su Utopía llamada $P e$ regrinaciones de Luz de Día, de 1887. Allí el autor describió la mentalidad de las élites que fueron responsables de construir las nuevas repúblicas, y las características del mercado mundial en 1820. Allí puso énfasis en el alto nivel de desarrollo alcanzado por las naciones industrializadas y argumentó que por ésta y otras razones el posible futuro económico de América Latina se basaría en la exportación de materias primas.

En el segundo ciclo, el dilema de la industrialización y la identidad exporta- 
dora fue reflejado en la famosa novela de Rodó, Ariel, de 1900. En ella el autor presentó una identidad alternativa a la del Calibán materialista del norte, en una tradición más espiritualista y valorativa. Ésta debería recibir con discreción la tecnología, el comercio y el pragmatismo del norte de América.

En realidad, la opción industrial no aparecía con claridad. Más bien, muchos gobernantes latinoamericanos fueron muy explícitos en adoptar la opción de consolidar a sus países como exportadores de materias primas. El presidente peruano Augusto B. Leguía dijo en 1924: 'hemos sido, somos y seremos exportadores de materias primas'. La bonanza de este ciclo terminó con el Stock Exchange Crash de Nueva York, en 1929. A consecuencia de esto, algunas naciones optaron por la sustitución de importaciones. El Perú no lo hizo.

A lo largo del tercer ciclo, aun cuando la exportación de materias primas todavía rendía réditos y la industrialización se presentaba promisoria en países como Argentina y Brasil, fue claro que estas naciones realmente no se estaban desarrollando y entonces apareció el concepto de subdesarrollo. El actual presidente de Brasil, Fernando Enrique Cardoso, participó en la generación que produjo la literatura del subdesarrollo y las tesis de dominación y dependencia.

En los años sesenta, Óscar Lewis nos presentó una 'subcultura de la pobreza' para México en su libro Los hijos de Sánchez. Por oposición, al inicio de la década de los setenta los latinoamericanos nos deleitamos con la cultura del realismo mágico o de lo real-maravilloso de Gabriel García Márquez en su novela Cien años de Soledad, revalorando y hasta sobrevalorando nuestra dimensión mágica y nuestra irrenunciable capacidad de soñar. Fue la cultura que nos identificó más allá del liberalismo, del capitalismo, del arte psicodélico o de cualquier corriente extranjera. El premio Nóbel de Literatura otorgado a García Márquez en 1982 robusteció la identidad latinoamericana.

El escritor brasileño Jorge Amado reafirmó el valor de nuestra identidad mestiza cuando dijo que en América Latina: 'Los dioses y los hombres se han mezclado para siempre, felizmente. Sí, felizmente'.

Fue una literatura que alimentó nuestras almas pero que no pudo alimentar nuestros cuerpos. El modelo exportador propició la marginación económica, educativa y social de grandes sectores de la población y, lo que es peor, nos dio una identidad 'sin valor agregado'. Ésta, a la que podemos llamar 'identidad primario exportadora', se ha convertido en el gran reto del desarrollo.

\section{La cultura del subdesarrollo o el realismo de los noventa}

De acuerdo con la $\mathrm{CEPAL}^{2}$, la región enfrenta hoy un complejo mundo de logros no despreciables en diversos frentes económicos, sociales y políticos, pero también mantiene una relación de temas pendientes asociados a las recientes transformaciones, al peso no plenamente superado de la crisis de la deuda de los años ochenta y a problemas estructurales profundamente enraizados en su historia.

2. Juan Carlos Ramírez, asesor del secretario ejecutivo de la Comisión Económica para América Latina y el Caribe, CEPAL: La cultura del desarrollo. En Economía y cultura: la tercera cara de la moneda. Bogotá: CAB, 2001. 
De acuerdo con la misma fuente, el balance de esta década deja saldos positivos y otros negativos.

A pesar de que no se aplica de la misma manera a todas las naciones involucradas, lo positivo tiene que ver con el manejo económico en la corrección de desequilibrios fiscales, la reducción de la inflación, la aceleración del crecimiento de las exportaciones, el rescate y puesta en marcha de nuevos procesos de integración regional, la atracción de flujos importantes de inversión extranjera y en el restablecimiento del crecimiento económico ( $1 \%$ en los años ochenta y 3,3\% en los años noventa). Ha habido también un significativo progreso en el desarrollo de una institucionalidad macroeconómica fuerte, y, con cierto rezago, se ha venido enfrentando los nuevos retos institucionales en otros campos, como la regulación de los mercados financieros, el fomento de prácticas competitivas y la regulación de los servicios públicos y sociales. Respecto al desarrollo social, se aumentó el gasto público, con lo que se redujo en algunas naciones, no en todas ni en grado suficiente, la proporción de la población en estado de pobreza. A otro nivel se registra el renacimiento de la vida local, la extensión de los sistemas democráticos, la conquista de derechos, el reconocimiento de la contribución de las mujeres a la sociedad y la incorporación gradual de la agenda del desarrollo sostenible.

En cuanto a lo negativo, el crecimiento económico y el aumento de la productividad han sido frustrantes durante la última década. De hecho, según la CEPAL, sólo tres países de la región alcanzaron en ambas variables registros iguales o su- periores a los obtenidos en los tres decenios anteriores a la crisis de la deuda. $\mathrm{La}$ inestabilidad del crecimiento económico y la frecuencia de las crisis financieras indican que no se han eliminado las causas de inestabilidad, y que algunas incluso pueden estar hoy más acentuadas. Muchas empresas, especialmente medianas y pequeñas, no han logrado adaptarse al nuevo contexto. Como consecuencia, ha aumentado el desempleo abierto (de 6\% a $9 \%$ para el conjunto de los países latinoamericanos) y la informalidad. La enorme disparidad educativa ha afectado la distribución del ingreso. Este hecho está, sin duda, tras los problemas de cohesión social y gobernabilidad que afectan crecientemente a la región.

A la luz de los aspectos negativos, es claro que no existen soluciones universales a los problemas de reducción de déficit fiscales, de inflación, de inserción en la economía mundial, de mayor participación del sector público, ni de mayor eficiencia del Estado. Ha quedado demostrado que no hay un modelo único de manejo macroeconómico que garantice los resultados deseados ni una forma única de combinar los esfuerzos conjuntos de los sectores público y privado. En algunos casos las reformas han sido la causa de los problemas, por lo que se hace necesario 'reformar las reformas'. Son muchísimas las medidas correctivas puntuales que se pueden ensayar para lograr el funcionamiento de los mercados competitivos y la participación de la sociedad civil, corregir las 'fallas del mercado' como 'las fallas del gobierno' e incluso para construir y reconstruir instituciones. Esto último, afirman sin dudas los expertos de la CEPAL, es una de las tareas más complejas que enfrenta la región. 


\section{Propuestas y problemas para una reorientación de los patrones de desarrollo}

Frente a una interminable lista de sugerencias y mandatos aparece una propuesta interesante para la reorientación de los patrones de desarrollo de la región, la que nos sugiere como eje principal del desarrollo el logro de la equidad, es decir, la reducción de la desigualdad social en sus múltiples manifestaciones. La CEPAL ha llegado al convencimiento de que ésta es 'la vara fundamental para medir la calidad del desarrollo' 3 . Se ha comprendido que el crecimiento económico es sólo un indicador de la verdadera meta, que es el desarrollo más integrador en términos sociales, y sostenible en términos ambientales, y que todo ello debe estar acompañado de esfuerzos sustanciales por construir tejidos sociales que permitan desarrollar sociedades más integradas. La recomendación para este desarrollo integral es tener dos puntales fundamentales o 'dos llaves maestras': educación y empleo.

El tema del empleo es sumamente complejo visto desde las reformas macroeconómicas, pero muy simple desde el punto de vista educativo. El paradigma cultural por excelencia en América latina es la educación. En el Perú, el gran movilizador social, aparte de las oportunidades laborales, es la oportunidad de educar a los hijos para que logren mejores trabajos y una ubicación menos excluyente en la sociedad. A pesar de ello, existe una gran disparidad en los países de la región en cuanto a las prioridades que se otorgan al gasto público social, especialmente al desarrollo del capital

3. Ibid. humano. Las propuestas educativas vigentes son sumamente interesantes y adecuadas a los tiempos, los currículos están privilegiando las capacidades y habilidades para 'aprender a aprender', pero esto no basta. El presupuesto dedicado a la educación no garantiza en absoluto que las metas curriculares serán alcanzadas algún día cercano. Una alternativa novedosa y esperanzadora es la capacitación en el manejo de los nuevos instrumentos que ofrecen la comunicación, la información y la industria cultural. Sin lugar a dudas, la 'economía de mercado' y la globalización perfilan la nueva identidad de América Latina, que ha recibido el mensaje de la competitividad como único camino de supervivencia.

\section{5. ¿Qué papel le corresponde a la cultura en la generación del desarrollo?}

Vemos que, a inicios del siglo XXI, el fracaso de todos los ensayos y recetas desarrollistas nos confrontan con un problema de dimensiones inimaginables por la extensión de la pobreza, la escasez y destrucción de los recursos y el papel secundario que juega la educación. Por ello, es entendible que los especialistas en el desarrollo que están 'más preocupados por alimentar a los hambrientos y por eliminar la pobreza' se 'irriten a menudo ante un interés por la cultura que les parece prematuro en un mundo donde las privaciones materiales son todavía numerosas'. ¿Cómo, se preguntan, puede hablarse de cultura -poesía, música, pintura-mientras la gente muere de hambre, de desnutrición o de enfermedades que serían fáciles de prevenir?

Ciertamente, esta posición separa de manera artificial los elementos y las eta- 
pas de la vida y asume a la cultura como la última de las necesidades humanas: es la que puede esperar y ser satisfecha cuando todo lo material esté 'puesto en orden'. Esta opinión revela un prejuicio extendido según el cual los pobres no crean ni reciben cultura e ignora otras dimensiones de la cultura como, por ejemplo, el papel de la cultura en la economía, que es muy importante por varias razones:

i. Porque la cultura involucra ciencia, tecnología y economía en general.

ii. Porque la cultura genera actitudes y éstas son determinantes para favorecer o frenar el desarrollo.

iii. Porque la capacidad de crear cultura requiere de políticas educativas muy agresivas.

iv. Porque el papel de la cultura en la economía no sólo se refleja en la cultura productiva y material, sino en la posibilidad de generar recursos económicos a partir de la cultura en su dimensión de arte y artesanía y patrimonio histórico cultural, como en el caso del Perú.

v. Porque en el mundo globalizado la cultura está íntimamente ligada a la comunicación.

Los países latinoamericanos no pueden esperar a desarrollarse para dar importancia a la cultura. El proceso globalizador no espera y, por ello mismo, tienen más bien que encontrar salidas a las condiciones actuales para potenciar el papel de la cultura en la economía. El gran aliado de este proceso es la comunicación, siempre y cuando ella pase por un proceso de democratización. Latinoamérica no podrá competir con la producción de tecnología, pero sí podrá realizar esfuerzos para lograr una mayor circulación de la cultura mediante una suerte de democracia comunicacional. Ésta, junto con la educación, son las dos grandes y quizá las únicas alternativas para la forja de identidades culturales que puedan estar en capacidad de negociar con la globalización.

La recomendación del ex ministro de cultura de Colombia Mejía Arango, es perfectamente aplicable al resto de la región:

En la medida en la que los responsables de la política estimulen la creación, provean las condiciones, las herramientas, los medios, las tecnologías que hacen posible crear y garanticen el derecho al libre acceso a los bienes y servicios culturales podremos avanzar hacia el futuro con dignidad. De ahí que se deben estimular y fomentar las pequeñas y medianas empresas culturales.

El resultado de la investigación sobre el aporte de las industrias culturales al desempeño económico del país, podría considerarse como un vivero o como una incubadora de pequeñas y medianas empresas, con proyecto de país. Empresas multiculturales, empresas que sepan articular, con equilibrio, todos los eslabones del ciclo de vida de un bien cultural, la creación, la producción, la distribución, el consumo. Empresas que generen productos cualificados y, por tanto, competitivos, que tiendan hacia la autosostenibilidad, que generen empleo. Empresas que surjan de la base, que representen los sueños y las identidades de las comunidades, que generen productos que simbolicen lo que somos como nación, como región, que dignifiquen la oferta y la hagan circular dentro y fuera del país. Empresas que inauguren nuevos circuitos de distribución y 
comercialización de los bienes y los servicios culturales y que contribuyan a su democratización» 4 .

Podemos concluir en que el fracaso del modelo primario exportador y de las recetas desarrollistas nos obliga a repensar la cultura 'como mediadora entre la realidad y los sueños' 5 para convertirla nuevamente en el conocimiento que realice nuestros sueños. No se trata de generar nuevas recetas, sino corrientes de opinión que convenzan a nuestros pueblos de que sí podemos identificar nuestras fortalezas culturales y administrarlas para satisfacer nuestras necesidades y alcanzar nuestros sueños.

Necesitamos convencer a los hacedores de políticas en la región y a los hacedores de políticas a nivel mundial de que las destrezas educativas y la cultura son los únicos caminos para el desarrollo. Después de todo, la economía del conocimiento sólo se ubicará allí donde las sociedades posean altos indicadores de capital humano y social.

4. Ministro de Cultura de Colombia (2001).

5. Ibid. 